\title{
S-Phase-Specific Transcription Regulatory Elements Are Present in a Replication-Independent Testis-Specific H2B Histone Gene
}

\author{
INHWAN HWANG ${ }^{+}$AND CHI-BOM CHAE* \\ Department of Biochemistry, University of North Carolina, Chapel Hill, North Carolina 27599-7260
}

Received 12 October 1988/Accepted 6 December 1988

\begin{abstract}
The testis-specific H2B histone (TH2B) gene is expressed in pachytene spermatocytes during meiotic prophase I in the absence of any significant DNA synthesis. Unlike somatic histones, synthesis of testis-specific histones is not affected by inhibitors of DNA synthesis. A genomic rat TH2B gene was cloned by using a DNA fragment derived from TH2B cDNA as a probe. Expression of the cloned TH2B was investigated by gene transfer experiments. From these studies, we found that the $5^{\prime}$ upstream region of the cloned TH2B gene contained S-phase-specific transcription elements which regulated expression of a reporter gene in an S-phase-specific manner. The S-phase-regulatory element was found to be located in two regions containing CCAAT elements between -153 and -110 base pairs (bp) and an octamer element (ATTTGCAT) between -109 and $-84 \mathrm{bp}$. The two regions were required for a maximal stimulation of transcription of the cloned TH2B gene in $S$ phase. On the other hand, only the octamer element was reported be important for the S-phase-specific transcription of human H2B gene. Since the synthesis of the TH2B histone is independent of DNA synthesis and specific for pachytene spermatocytes in vivo, the presence of the S-phase-specific transcription regulatory elements in the TH2B gene is surprising.
\end{abstract}

During $S$ phase in most eucaryotic cells, newly replicated DNA is assembled into chromatin by histone proteins (36). Therefore, there is a great demand for histones during $S$ phase, when DNA replication occurs. Cells meet the demand for histone proteins by two different mechanisms: increased expression of histone genes and stabilization of histone mRNAs during the $S$ phase $(19,29,30,35,41,44)$. In this manner, cells achieve more than a 10 -fold increase in histone mRNA during the $\mathrm{S}$ phase. The coupling of histone and DNA synthesis has been well established, but the mechanism of coupling is not clearly understood. Recently attention has been focused on the molecular mechanisms of the cell cycle-dependent expression of histone genes and the stabilization of mRNAs during $\mathrm{S}$ phase. The S-phase-specific histone gene transcription appears to be regulated by cisacting DNA elements present $5^{\prime}$ of histone genes $(3,23,31$, $40,42)$. Also, histone mRNAs appear to have a sequence element(s) for stabilization of the mRNAs during the $\mathrm{S}$ phase of the cell cycle $(1,7,29,39,44)$. The $3^{\prime}$ noncoding region of the histone mRNA has a highly conserved hairpin structure that appears to influence S-phase-specific stability of histone mRNAs $(7,39,44)$.

There are histone variants which are cell cycle-independent and cell type specific. One of the cell cycle-independent variants is the human H3.3, which has an intron and encodes polyadenylated mRNA (46). The best-known examples of cell type-specific histones are the avian erythrocyte-specific H5 $(11,45)$ and the mammalian testis-specific histones $(4$, 27). During spermatogenesis, testis-specific histones (TH1, TH2A, and TH2B) are synthesized in the mammalian testis in the absence of DNA replication, and these histones replace the corresponding somatic histones $(6,27)$. Although the existence of testis-specific histones has long been known, only recently have the testis-specific histone genes been isolated. Therefore, the mechanism for regulation of

\footnotetext{
* Corresponding author.

† Present address: Department of Molecular Biology, Massachusetts General Hospital, Boston, MA 02144.
}

tissue-specific expression of these genes is totally unknown. Recently we cloned a testis-specific histone H2B (TH2B) cDNA from rat testis (21). RNA blot hybridization experiments showed that $\mathrm{TH} 2 \mathrm{~B}$ gene expression is specific for testis, in agreement with the analysis of histones by others $(4,27)$. Also, in situ cytohybridization shows that transcription of this gene is confined to pachytene spermatocytes during spermatogenesis (21). Others have also reported cloning of the testis-specific H1 (TH1) gene (8). The TH2B cDNA has a conserved coding region except for a stretch of nine amino acids at the $\mathrm{N}$-terminal region, starting at the third amino acid, and other minor changes in the N-terminal region. The $3^{\prime}$ nontranslated region of the TH2B mRNA has a sequence very similar to that of a somatic H2B mRNA, including the conserved hairpin structure involved in histone mRNA processing (21).

We have also cloned a 1.4-kilobase $(\mathrm{kb})$ genomic fragment containing the TH2B gene of rat and sequenced the gene including the 5 '- and 3 '-flanking sequences. The 5' upstream region of the TH2B gene contains several conserved sequence elements, including an octamer sequence (ATTTG CAT) found in a human somatic H2B gene (43). Since the octamer element is responsible for S-phase-specific transcription of the human $\mathrm{H} 2 \mathrm{~B}$ gene $(14,24)$, it is possible that the TH2B octamer may have a similar function. We tested this possibility in mouse embryo fibroblast cells by gene transfer experiments. We report here that the 5' upstream region of the TH2B gene contains the regulatory element(s) for S-phase-specific transcription and that the S-phase-regulatory elements (SREs) are located in two regions, one containing CCAAT elements between -153 and -110 base pairs (bp) and the other containing the octamer element between -109 and -42 bp from the transcription initiation site. These two elements appear to be additive for maximal activation of S-phase-specific transcription.

\section{MATERIALS AND METHODS}

Molecular cloning of the genomic TH2B. A rat genomic HaeIII library established in Charon 4A (38) (a gift from Dr. 


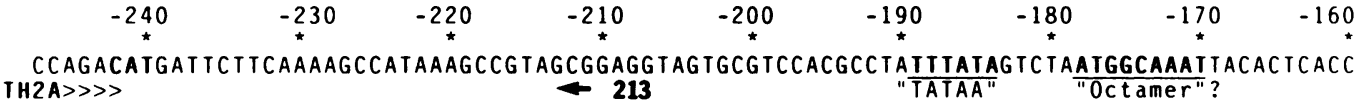

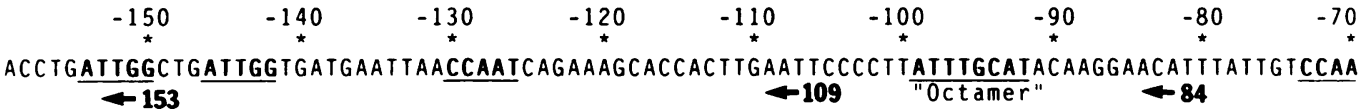

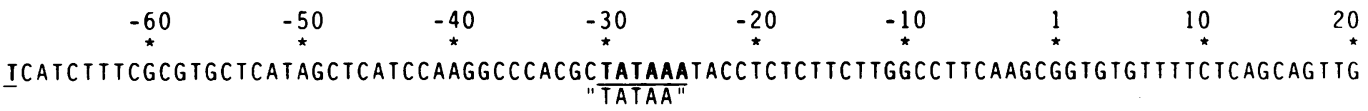

$$
\begin{aligned}
& 30 \quad 40 \quad 50 \quad 60 \\
& \text { GAACTGITTIGAGACGITCCAGTGGACAAACTTATTTTICCACG ATG CCG GAG GTG TCG GCA } \\
& \text { Met Proglu Val Ser Ala } \\
& <<<<\text { TH2B }
\end{aligned}
$$

FIG. 1. Sequence of the $5^{\prime}$ upstream region of the cloned TH2B gene. The two translation initiation sites for the TH2B and TH2A genes are indicated. Four copies of the CCAAT box are underlined. Also, two copies of the TATAA box and the octamer motif are indicated. The endpoints of the deletion mutants are indicated by arrows.

Sargent) was screened with a ${ }^{32} \mathrm{P}$-labeled 40 -mer complementary to the 5 ' nontranslated region of the TH2B cDNA. A 1.4-kb DNA fragment containing the TH2B gene was isolated from a lambda phage clone and subcloned into M13mp19 phage RF DNA (MTH2B). The DNA was sequenced by the chain termination method (37) after sequential deletions from one end of the insert were made as described by Dale et al. (10).

Isolation of a DNA fragment with defined ends. To construct a fusion gene with the $5^{\prime}$ upstream region and a reporter gene, that for chloramphenicol acetyltransferase (CAT), the TH2B upstream region with defined ends was isolated as follows. Single-stranded M13mp19 DNA containing the TH2B gene (MTH2B) was hybridized with the oligonucleotide (40-mer) whose $5^{\prime}$ end corresponds to one nucleotide upstream of the translation initiation codon and whose $3^{\prime}$ end is 41 bases upstream. The hybridized oligonucleotide was extended toward the $5^{\prime}$ upstream region of the TH2B gene with the Klenow fragment of Escherichia coli DNA polymerase $I$ in the presence of $4 \mathrm{dNTPs}$, and then the DNA was treated with mung bean nuclease and T4 DNA polymerase to generate a blunt end at the $5^{\prime}$ end to the start of translation. The other side was digested with HincII to give a 554-bp fragment containing the TH2B upstream region (see Fig. 4). This method generates DNA fragments with defined ends.

Construction of a fusion gene with the TH2B upstream sequence and the CAT coding region. pSV2CAT (16) (gift from Bruce Howard) was digested with $A c c I$, made flush- ended with Klenow fragment, and then digested again with HindIII. A HindIII-RsaI DNA fragment (136 bp) containing a multiple cloning site was isolated from pSP65 (28) and inserted into the HindIII and AccI sites of pSV2CAT, replacing the simian virus 40 promoter region (pLCAT). The 554-bp TH2B promoter region from one base upstream of the AUG codon was inserted into the SmaI site of pLCAT to produce a TH2B-cat fusion gene (pTH2BCAT) (see Fig. 4).

Construction of mutants. Sequential deletions of the $5^{\prime}$ upstream region of the TH2B gene were made by digestion with appropriate restriction endonucleases (26). The deletion mutants were fused with the bacterial cat gene in pLCAT containing a multicloning site upstream of the CAT coding region.

Short-term assay of S-phase-dependent transcription of the cloned TH2B gene. Cultures ( 70 to $80 \%$ confluent) of mouse embryo fibroblast $\mathrm{C} 3 \mathrm{H} 10 \mathrm{~T} 1 / 2$ cells were plated at a density of $10^{4}$ cells $/ \mathrm{cm}^{2}$. The cells were incubated with basal medium Eagle (BME) containing $10 \%$ heat-inactivated fetal bovine serum. The next day, a mixture of $6 \mu \mathrm{g}$ of pTH2BCAT and $5 \mu \mathrm{g}$ of pRSV $\beta$-gal DNA (12) (gift from William J. Rutter) was added to each $10-\mathrm{cm}$ dish as DNA-CaPO ${ }_{4}$ coprecipitates (15). The cells were incubated at $37^{\circ} \mathrm{C}$ in a humidified chamber with $5 \% \mathrm{CO}_{2}$ for 12 to $15 \mathrm{~h}$. Then the cells were rinsed with Hanks balanced salt solution lacking $\mathrm{Ca}^{2+}$ and $\mathrm{Mg}^{2+}$ (HBSS), and fresh medium containing $2 \mu \mathrm{g}$ of aphidicolin (Natural Products Branch, National Cancer Institute) per $\mathrm{ml}$ was added. After incubating for $24 \mathrm{~h}$ with the aphidicolin, the cells were rinsed with HBSS twice and refed

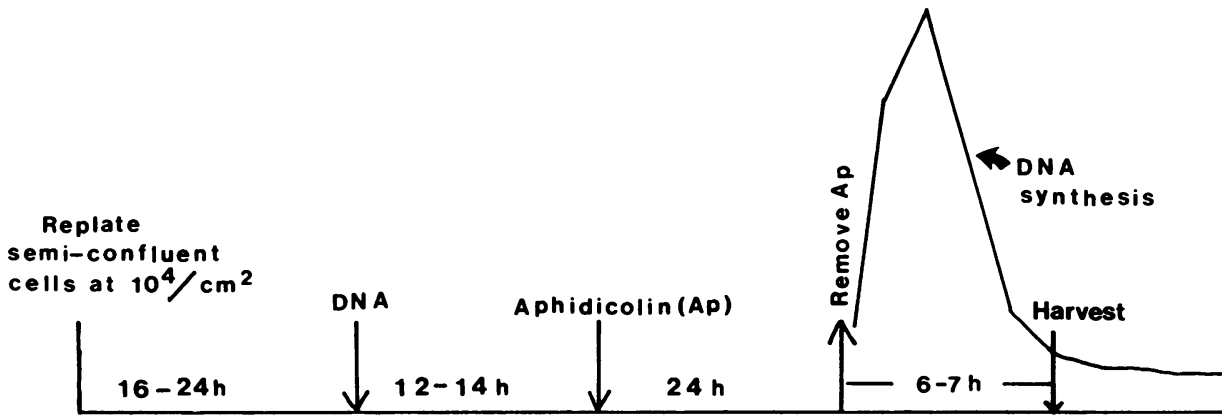

FIG. 2. Schematic diagram of a transient assay for the S-phase-dependent transcription of transfected DNAs. See Materials and Methods for details. 
with fresh medium without aphidicolin to release the cells from the aphidicolin block. To determine the degree of DNA synthesis after release from the aphidicolin block, $\left[{ }^{3} \mathrm{H}\right]$ thymidine $(72 \mathrm{Ci} / \mathrm{mmol} ; \mathrm{ICN})$ was added to the cultures $(2 \mu \mathrm{Ci} / \mathrm{ml})$ at each time point. The cells were incubated for 15 min to label DNA, and the amount of label in acid-insoluble material was determined as described before (9). $\beta$-Galactosidase activity encoded by the pRSV $\beta$-gal was assayed as described previously (2), and portions of cell lysates containing equal amounts of $\beta$-galactosidase activity were used to assay CAT activity (15). When necessary, the $\left[{ }^{14} \mathrm{C}\right]$ acetylchloramphenicol spots were scraped from the thin-layer chromatography plates, and the radioactivity was determined in a scintillation counter.

Nuclear run-on transcription assay. For a nuclear run-on transcription assay, cells released from a 24-h aphidicolin block for $2 \mathrm{~h}$ were used for the preparation of $\mathrm{S}$ phase nuclei. Non-S-phase nuclei were prepared from the cells, which were kept in the aphidicolin-containing medium for $26 \mathrm{~h}$. Nuclei were prepared as described previously (34). For a transcription reaction, nuclei were incubated with $200 \mu \mathrm{Ci}$ of $\left[\alpha-{ }^{32} \mathrm{P}\right]$ GTP $(800 \mathrm{Ci} / \mathrm{mmol}$; New England Nuclear) as described by Groudine et al. (18). Total RNA was purified with a 3-ml Sephadex G-50 spin column. For hybridization of RNA to the various probes, $2 \mu \mathrm{g}$ of appropriate DNAs was immobilized onto a nitrocellulose filter secured on a slot blot apparatus. The immobilized DNAs were fragments containing a rat $\mathrm{H} 2 \mathrm{~B}$ gene, $\beta$-galactosidase, cat gene sequences, and lambda DNA. The nitrocellulose filter was incubated at $80^{\circ} \mathrm{C}$ for $3 \mathrm{~h}$ in a vacuum oven and prehybridized for $5 \mathrm{~h}$ at $42^{\circ} \mathrm{C}$ in $50 \%$ formamide- $10 \mathrm{mM}$ Tris hydrochloride ( $\mathrm{pH} 7.4)-5 \mathrm{mM}$ EDTA-0.15 M NaCl-0.1\% sodium dodecyl sulfate (SDS)$1 \times$ Denhardt solution- $500 \mu \mathrm{g}$ of yeast tRNA per ml. Hybridization was carried out in the prehybridization solution with labeled transcripts for $30 \mathrm{~h}$ at $42^{\circ} \mathrm{C}(21,26)$. The nitrocellulose filter was washed with $2 \times \mathrm{SSC}(1 \times \mathrm{SSC}$ is $0.15 \mathrm{M} \mathrm{NaCl}$ plus $0.015 \mathrm{M}$ sodium citrate) twice at room temperature and then with $0.1 \times \mathrm{SSC}-0.1 \%$ SDS at $55^{\circ} \mathrm{C}$ for $1 \mathrm{~h}$.

Stable transformant with the integrated TH2BCAT fusion gene. To obtain stable transformants, $\mathrm{C} 3 \mathrm{H} 10 \mathrm{~T} 1 / 2$ cells were cotransfected with $9 \mu \mathrm{g}$ of pTH2BCAT and $1 \mu \mathrm{g}$ of pRSVneo (17) according to Lassar et al. (25). Stable colonies resistant to G-418 (Geneticin; Gibco) were isolated and grown separately. Each colony was assayed for CAT activity.

Dot blot hybridization of RNA. RNA was extracted from $\mathrm{C} 3 \mathrm{H} 10 \mathrm{~T} 1 / 2$ cells after lysis in guanidine isothiocyanate solution and subsequent $\mathrm{CsCl}$ gradient centrifugation (5). Total RNA $(3 \mu \mathrm{g})$ was denatured with formamide and formaldehyde (26) and applied to a nitrocellulose filter secured in a dot blot apparatus. The nitrocellulose filter was incubated at $80^{\circ} \mathrm{C}$ in vacuo and prehybridized and hybridized with probes complementary to the endogenous mouse $\mathrm{H} 2 \mathrm{~B}$, TH2BCAT, and neomycin-resistant genes. The probes were labeled by a random priming reaction as described before (13).

\section{RESULTS}

Structure of the cloned TH2B gene. We cloned a DNA fragment containing the $\mathrm{TH} 2 \mathrm{~B}$ gene from a rat genomic library established in Charon 4A (38). To isolate a genomic copy of the TH2B cDNA, we used a synthetic $40-$ mer complementary to the $5^{\prime}$ untranslated region of the $\mathrm{TH} 2 \mathrm{~B}$ cDNA which shows complete sequence divergence from the corresponding region of a rat $\mathrm{H} 2 \mathrm{~B}$ gene (21). The sequence of the 5'-flanking region of the gene is shown in Fig. 1. The cloned genomic copy of the TH2B gene has the same sequence as that of the cloned cDNA, including the $5^{\prime}$ and $3^{\prime}$ untranslated regions (21). This observation suggests that the TH2B gene is the genuine genomic copy of the cloned TH2B cDNA. Thus, the cloned 5'-flanking sequence of this genomic clone contains the transcription promoter. Of particular interest was the presence of an octamer sequence, ATTTGCAT, and CCAAT sequence $30 \mathrm{bp}$ upstream of the octamer motif. The octamer sequence in the human $\mathrm{H} 2 \mathrm{~B}$

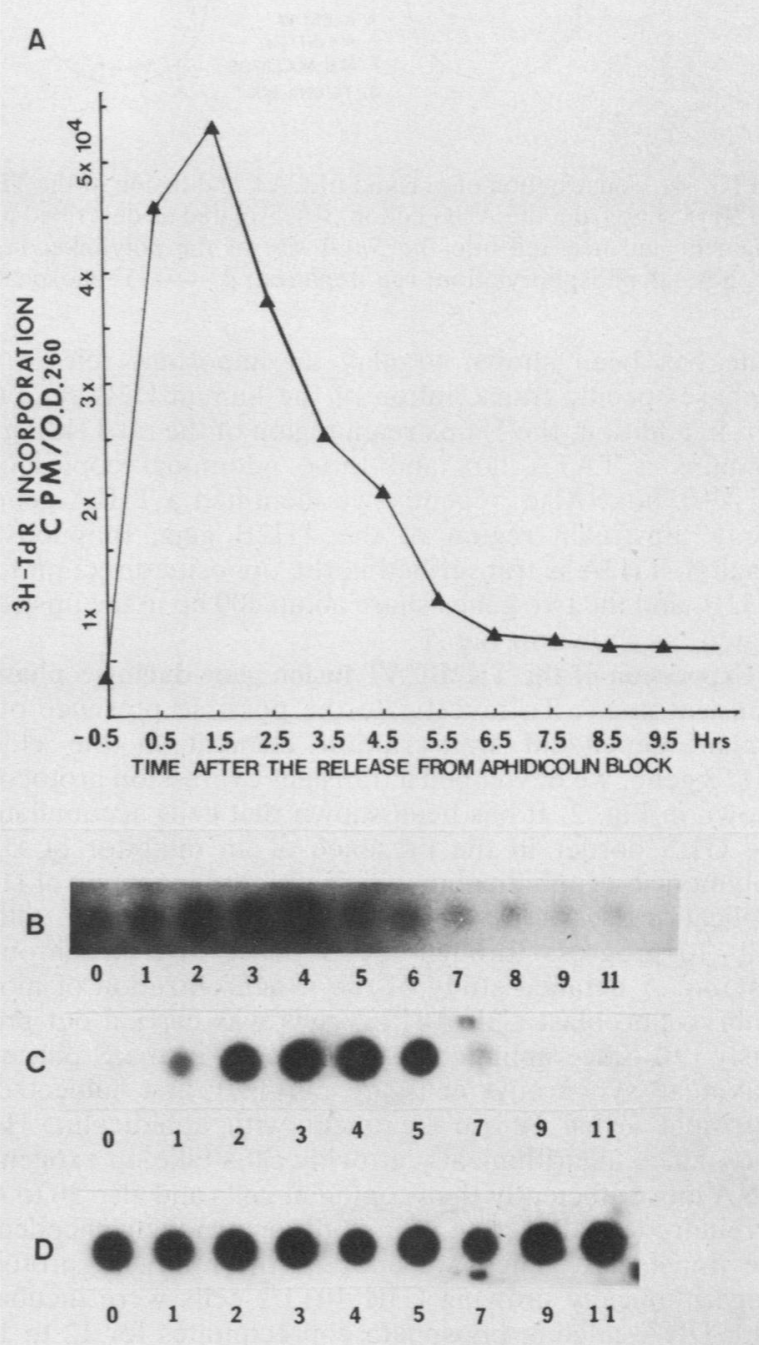

FIG. 3. Labeling of $\mathrm{C} 3 \mathrm{H} 10 \mathrm{~T} 1 / 2$ cells with $\left[{ }^{3} \mathrm{H}\right]$ thymidine after release from the aphidicolin block and the $\mathrm{S}$-phase-dependent transcription of the transfected $\mathrm{TH} 2 \mathrm{~B}$ gene. $\mathrm{C} 3 \mathrm{H} 10 \mathrm{~T} 1 / 2$ cells were transfected with $6 \mu \mathrm{g}$ of MTH2B and $5 \mu \mathrm{g}$ of pRSVneo and exposed to aphidicolin for $24 \mathrm{~h}$ as described in the text. After release from the aphidicolin block, the cells were harvested at several time points as indicated, and the levels of DNA synthesis (A) were monitored by $\left[{ }^{3} \mathrm{H}\right]$ thymidine $\left({ }^{3} \mathrm{H}-\mathrm{TdR}\right)$ incorporation. The mRNAs for endogenous mouse H2B (B), transfected rat TH2B (C), and RSVneo (D) genes were analyzed by dot blot hybridization as described in the text. MTH2B is the 1.4-kb rat DNA containing the TH2B gene inserted into M13mp19. Replicative form of the DNA was used. The 1.4-kb DNA contains 485 bp of the upstream region of TH2B, the TH2B gene ( $470 \mathrm{bp}$ ), and 445 bp of 3'-flanking sequence. Total RNA $(3 \mu \mathrm{g})$ was denatured and fixed onto a nitrocellulose filter for the hybridization analysis as described in the text. 


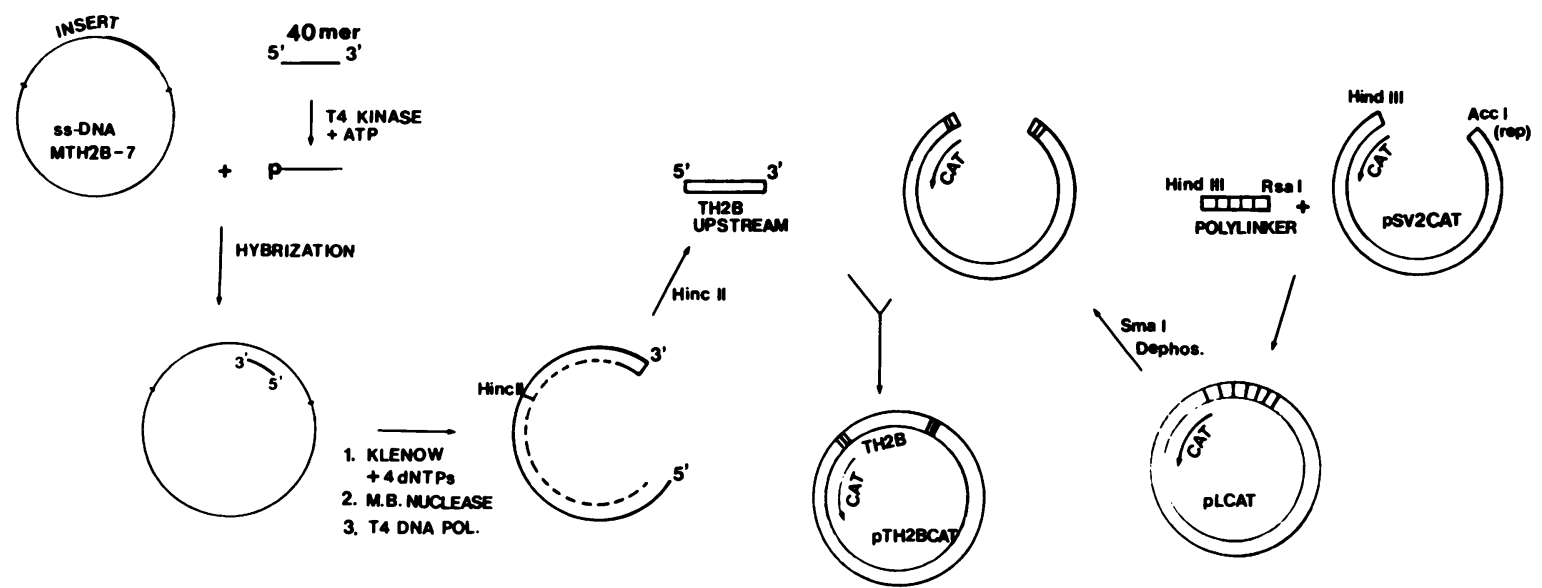

FIG. 4. Construction of plasmid pLCAT and fusion of the TH2B upstream sequence with the bacterial cat gene. The 5'-flanking region of TH2B (554 bp from the AUG codon) was isolated as described in the text by using an oligonucleotide primer to produce defined ends of DNA fragment and inserted into the SmaI site of the polylinker region of pLCAT. M.B., Mung bean; ss, single-stranded; pol., polymerase; Dephos., dephosphorylation; rep, repaired; $p \_$, 5'-phosphate.

gene has been shown to play an important role in the S-phase-specific transcription of the human H2B gene (14, $24)$. In addition, the $5^{\prime}$ upstream region of the rat TH2B gene contains a TATA box and three additional copies of a CCAAT box. Also, recently we identified a TH2A gene at the $5^{\prime}$ upstream region of the TH2B gene (unpublished results). TH2A is transcribed in the opposite direction from TH2B, and the two genes share about $200 \mathrm{bp}$ in the upstream region, as shown in Fig. 1.

Expression of the TH2BCAT fusion gene during $S$ phase: a transient assay. To investigate the possible presence of an S-phase-dependent transcription element in the cloned TH2B gene, we developed a transient expression protocol as shown in Fig. 2. It has been shown that cells accumulate at the $\mathrm{G} 1 / \mathrm{S}$ border in the presence of an inhibitor of DNA polymerase $\alpha$, aphidicolin, which inhibits elongation of DNA replication (9). Release from an aphidicolin block allows cells to progress through the $S$ phase in a synchronous fashion. A detailed study of the synchronization of mouse embryo fibroblast $\mathrm{C} 3 \mathrm{H} 10 \mathrm{~T} 1 / 2$ cells was carried out previously (9). Since aphidicolin arrests cells in the $S$ phase, to maximize synchrony, cells are normally first subjected to confluent arrest before treatment with aphidicolin. However, since logarithmically growing cells take up exogenous DNA more efficiently than confluent cells and also 30 to $40 \mathrm{~h}$ is required for detection of the protein products encoded by the transfected genes, we adopted the following protocol. Logarithmically growing $\mathrm{C} 3 \mathrm{H} 10 \mathrm{~T} 1 / 2$ cells were incubated with DNA-calcium phosphate coprecipitates for 12 to $15 \mathrm{~h}$ and rinsed free of the coprecipitates. The cells were incubated with a medium containing aphidicolin $(2 \mu \mathrm{g} / \mathrm{ml})$ for 24 $h$ to allow the non-S-phase cells to accumulate at the G1/S border (see Fig. 2 for the protocol). The cells subjected to the protocol described above showed a dramatic increase in DNA synthesis immediately after release from the aphidicolin block, as determined by labeling of DNA with $\left[{ }^{3} \mathrm{H}\right]$ thymidine (Fig. 3A). DNA synthesis reached a maximum in $1 \mathrm{~h}$ after release from the aphidicolin block and continued for 5 more hours. To ascertain that the level of endogenous mouse $\mathrm{H} 2 \mathrm{~B}$ mRNA as well as the mRNA transcribed from the transfected TH2B gene were increased in the $S$ phase of cells synchronized according to the protocol described above, RNA was extracted from the cells at various time points after release from the aphidicolin block and analyzed by dot blot hybridization with specific DNA probes. The result shows that the level of endogenous $\mathrm{H} 2 \mathrm{~B}$ and TH2B mRNA rose and fell in close parallel with the rate of DNA synthesis as the cells were allowed to enter the $S$ phase of the cell cycle (Fig. 3). The results suggest that expression of the TH2B gene in the cloned 1.4-kb DNA was regulated in an $\mathrm{S}$-phase-specific manner, like the endogenous $\mathrm{H} 2 \mathrm{~B}$ gene, when the gene was introduced into mouse embryo fibroblast cells. The expression of the cotransfected RSVneo gene was independent of DNA replication. The reason for the significant hybridization of the zero-time sample of the endogenous $\mathrm{H} 2 \mathrm{~B}$ could be due to the high background hybridization of the probe. The lower signals for the 4- and 7-h samples of RSVneo RNA are most likely due to the lower amount of transfected DNA. Both the plasmid containing the 1.4-kb DNA and RSVneo were introduced into the cells as a mixture.

To examine the possible S-phase-dependent expression of the cloned TH2B gene, the $5^{\prime}$ upstream region of the TH2B gene (554 bp from one base upstream of the AUG codon) was fused with the cat gene in the promoterless pLCAT plasmid to generate pTH2BCAT (Fig. 4). The upstream region of the TH2B gene with defined ends was obtained by a new method described in Materials and Methods and shown in Fig. 4. The pTH2BCAT $(6 \mu \mathrm{g})$ and pRSV $\beta$-gal (5 $\mu \mathrm{g})$ plasmids (12) were cotransfected into $\mathrm{C} 3 \mathrm{H} 10 \mathrm{~T} 1 / 2$ cells, and the cells were synchronized according to the protocol described above (Fig. 2). pRSV $\beta$-gal DNA was cotransfected to control the transfection efficiency among different dishes. The cells were harvested 6 to $7 \mathrm{~h}$ after release from the aphidicolin block. Cell extracts were prepared as described before (16), and $\beta$-galactosidase activity was determined (2). Portions of cell extracts which had the same amount of $\beta$-galactosidase activity were used to assay CAT activity to correct for variation in transfection efficiency. The activity of the Rous sarcoma virus promoter was independent of DNA replication (Fig. 3D). In the case of pTH2BCAT, CAT activity of the released cells (Fig. 5A, lane 6) showed a six- to sevenfold increase over that of cells maintained in the aphidicolin-containing medium (Fig. 5A, lane 5). As a control for cell cycle-independent expression, we introduced the pSV2CAT fusion gene. The cells transfected with pSV2CAT did not show any increase in CAT activity after release from the aphidicolin block (Fig. 5A, 


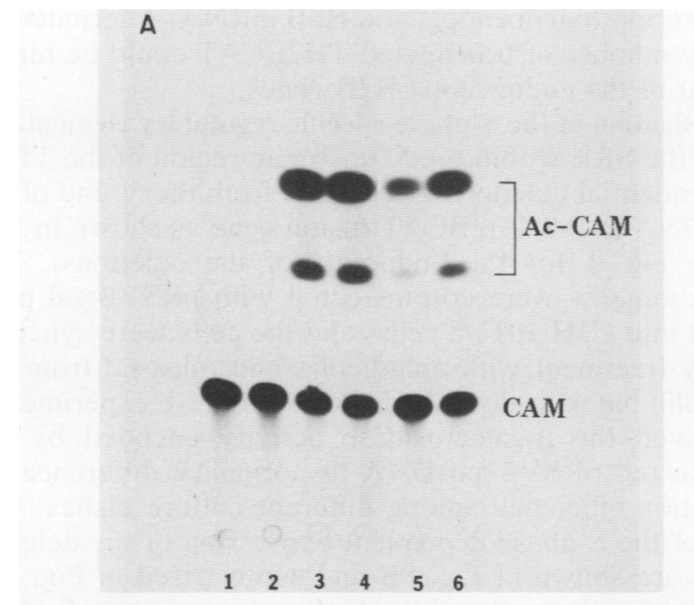

B

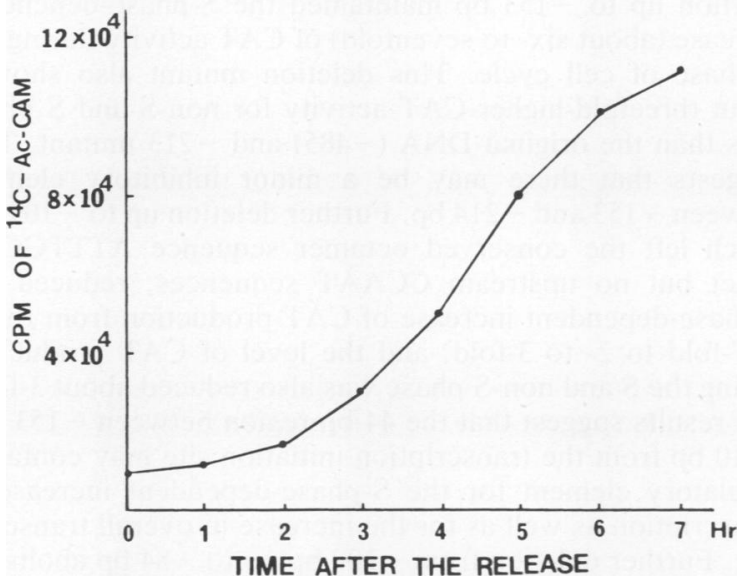

FIG. 5. S-phase-dependent synthesis of CAT under the control of the $5^{\prime}$ upstream sequence of the TH2B gene in a transient expression assay. Logarithmically growing $\mathrm{C} 3 \mathrm{H} 10 \mathrm{~T} 1 / 2$ cells were cotransfected with the DNAs being tested and the pRSV $\beta$-gal control, and the cells were treated with aphidicolin $(2 \mu \mathrm{g} / \mathrm{ml})$ for 24 h. Extracts were prepared from cells maintained in aphidicolin or from cells released from the aphidicolin block. $\beta$-Galactosidase activity was determined for correction of the difference in transfection efficiency, and CAT activity was determined as described in the text. $\left[{ }^{14} \mathrm{C}\right]$ chloramphenicol was used as the substrate. (A) Autoradiogram of the $\left[{ }^{14} \mathrm{C}\right]$ chloramphenicol (CAM) and acetylated chloramphenicol resolved by thin-layer chromatography. The two different forms of acetyl-chloramphenicol are indicated as Ac-CAM. (B) Radioactive spots were scraped from the plate, and the radioactivity was determined by liquid scintillation counting. (A) Cells exposed to aphidicolin for $30 \mathrm{~h}$ : lanes 1,3 , and 5 , pLCAT, pSV2CAT, and pTH2BCAT, respectively. Cells exposed to aphidicolin for $24 \mathrm{~h}$ and released for $6 \mathrm{~h}$ : lanes 2, 4, and 6, pLCAT, pSV2CAT, and pTH2BCAT, respectively. (B) Time course of production of CAT activity from the TH2BCAT fusion gene after release from the aphidicolin block.

lanes 3 and 4). The promoterless plasmid (pLCAT: see Fig. 4 for the structure) showed no CAT activity (Fig. 5A, lanes 1 and 2). The increased CAT activity encoded by TH2BCAT in the $S$ phase suggests that the 554-bp 5'-flanking region contains elements which regulate genes in an S-phasedependent manner.

The time course of the increase in CAT activity after synchronization of the cells transfected with TH2BCAT was determined (Fig. 5B). The CAT activity appeared to increase

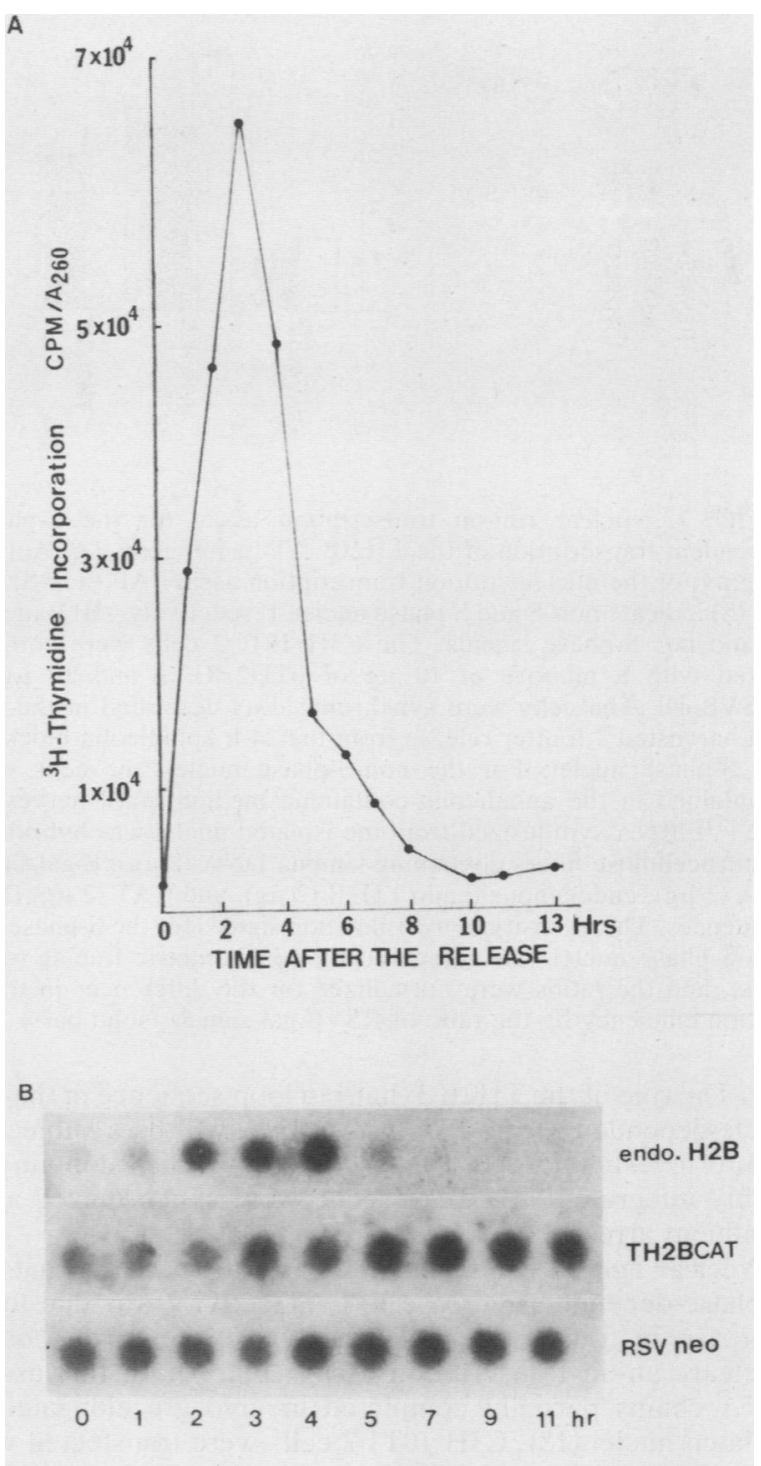

FIG. 6. S-phase-dependent expression of the TH2BCAT gene stably integrated into the chromosomes of $\mathrm{C} 3 \mathrm{H} 10 \mathrm{~T} 1 / 2$ cells. (A) ${ }^{3} \mathrm{H}$-labeling of DNA at different times after release from the aphidicolin block. (B) Dot blot hybridization analysis of the endogenous (endo.) H2B, TH2BCAT, and RSVneo mRNAs. C3H 10T1/2 cells were transfected with a mixture of pTH2BCAT and pRSVneo plasmids, and cells resistant to G-418 were selected. A clone which showed high CAT activity was synchronized after the confluent arrested cells were replated. Similar results were obtained with pooled cell clones.

$3 \mathrm{~h}$ after the release from the aphidicolin block and continued to increase until $7 \mathrm{~h}$. The continuous increase of CAT activity beyond the end of DNA replication suggests that the regulation of the cell cycle-dependent degradation of mRNA is lost in the TH2BCAT fusion gene. This is supported by the continuous rise of TH2BCAT mRNA beyond the end of DNA replication, as shown in Fig. 6. This is most likely due to the absence of the 3'-terminal hairpin loop involved in the cell cycle-dependent degradation of histone mRNA in the TH2BCAT gene. Others also reported that replacement or deletion of the 3 -terminal region of histone genes abolishes the cell cycle-dependent degradation of histone mRNA (32, 


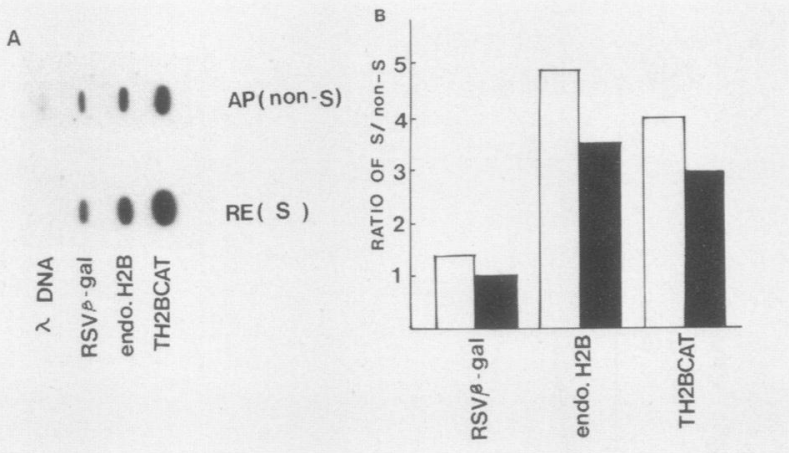

FIG. 7. Nuclear run-on transcription assay for the S-phasedependent transcription of the TH2BCAT fusion gene. (A) Autoradiogram of the nuclear run-on transcription assay. AP (non-S) and RE (S) indicate non-S and $S$ phase nuclei, respectively. (B) Ratios of $\mathrm{S}$ - and non-S-phase signals. The $\mathrm{C} 3 \mathrm{H} 10 \mathrm{~T} 1 / 2$ cells were cotransfected with a mixture of $10 \mu \mathrm{g}$ of pTH2BCAT and $10 \mu \mathrm{g}$ of pRSV $\beta$-gal. The cells were synchronized as described in the text and harvested $2 \mathrm{~h}$ after release from the 24-h aphidicolin block for the S-phase nuclei. For the non-S-phase nuclei, the cells were maintained in the aphidicolin-containing medium until harvested The $\left[{ }^{32} \mathrm{P}\right] \mathrm{RNA}$ synthesized from the isolated nuclei was hybridized to nitrocellulose filters containing lambda DNA $(2 \mu \mathrm{g}), \beta$-galactosidase $(2 \mu \mathrm{g})$, endogenous (endo.) H2B $(2 \mu \mathrm{g})$, and CAT (2 $\mu \mathrm{g})$ DNA sequences. The intensity of hybridization signals for the $S$-phase and non-S-phase nuclei was compared by densitometric tracing (open bars), and the ratios were normalized for the differences in transfection efficiency by the ratio of RSV $\beta$-gal signals (solid bars).

39). The role of the TH2B $3^{\prime}$ hairpin loop sequence in the cell cycle-dependent degradation of mRNA will be a subject of future investigation. In Fig. 6, the cells which contain the stably integrated TH2BCAT gene were synchronized after confluent arrest.

Nuclear run-on transcription assay. To ascertain that the S-phase-dependent increase in CAT activity was due to an increase in transcription of TH2BCAT, we carried out a nuclear run-on transcription assay (Fig. 7). In this assay, RNA chains partially completed in vivo are elongated in isolated nuclei (18). C3H 10T1/2 cells were transfected with the pTH2BCAT and pRSV $\beta$-gal plasmids. The transfected cells were synchronized and released from the aphidicolin block as described above. The cells were harvested $2 \mathrm{~h}$ after the release, and nuclei were prepared for a run-on transcription analysis. The transcription in the $S$-phase nuclei was compared with that in the non-S-phase nuclei. The ${ }^{32} \mathrm{P}$ labeled RNA synthesized from the isolated nuclei was hybridized to lambda, H2B, cat, and $\beta$-galactosidase DNA sequences fixed onto a nitrocellulose filter, and the intensities of hybridization signals were compared by densitometric tracing of the autoradiograms. The $S$ phase/non-S phase ratios of hybridization signals are shown in Fig. 7B (open bars). To account for possible differences in transfection efficiency, the $S$ phase/non-S phase ratios of the endogenous $\mathrm{H} 2 \mathrm{~B}$ and TH2BCAT signals were normalized by dividing the values with the ratio of the $\beta$-galactosidase signals (solid bars in Fig. 7B). The transcription of the endogenous $\mathrm{H} 2 \mathrm{~B}$ genes was 3.5-fold higher in the $S$ phase nuclei than in the non-S phase nuclei, and that of the TH2BCAT gene was about 3 -fold higher in the $S$ phase nuclei. The nuclear run-on assay clearly shows that the $5^{\prime}$ upstream region of the TH2B gene contains a regulatory element which stimulates transcription in $\mathrm{S}$ phase. The somewhat higher hybridization signal for TH2B than for endogenous H2B could be due to the longer cat transcript than in endogenou H2B mRNA. Alternatively, the copy number of transfected TH2BCAT could be higher than that of the endogenous $\mathrm{H} 2 \mathrm{~B}$ genes.

Identification of the S-phase-specific regulatory element. To identify the SRE within the $5^{\prime}$ upstream region of the TH2B gene, sequential deletions were made from the $5^{\prime}$ end of the TH2B DNA in the TH2BCAT fusion gene as shown in Fig. $8 \mathrm{~A}$ (see Fig. 1 for the endpoints of the deletions). The deletion mutants were cotransfected with pRSV $\beta$-gal plasmid (12) into $\mathrm{C} 3 \mathrm{H} 10 \mathrm{~T} 1 / 2$ cells, and the cells were synchronized by treatment with aphidicolin and released from the aphidicolin block as described above. In these experiments, we assayed the $\beta$-galactosidase activity encoded by the cotransfected pRSV $\beta$-gal DNA to normalize differences in transfection efficiency among different culture dishes. The results of the $S$-phase-dependent expression of the deletion mutants are shown in Fig. 8B and summarized in Fig. 8A. The ratios for $\mathrm{S} /$ non-S and the CAT activity in non-S phase cells are averages of three independent experiments. The deletion up to $-153 \mathrm{bp}$ maintained the S-phase-dependent increase (about six- to sevenfold) of CAT activity during the $S$ phase of cell cycle. This deletion mutant also showed about threefold-higher CAT activity for non-S and S phase cells than the original DNA $(-485)$ and -213 mutant. This suggests that there may be a minor inhibitory element between -153 and -214 bp. Further deletion up to $-109 \mathrm{bp}$, which left the conserved octamer sequence ATTTGCAT intact but no upstream CCAAT sequences, reduced the $S$-phase-dependent increase of CAT production from the 6to 7 -fold to 2- to 3-fold, and the level of CAT production during the $S$ and non-S phase was also reduced about 3-fold. The results suggest that the 44-bp region between -153 and $-110 \mathrm{bp}$ from the transcription initiation site may contain a regulatory element for the S-phase-dependent increase in transcription as well as for the increase in overall transcription. Further deletion from -109 bp up to -84 bp abolished the S-phase-dependent production of CAT. Therefore, the 25-bp region between -84 bp and -109 bp contains another regulatory element for the $\mathrm{S}$-phase-dependent transcription of the TH2BCAT fusion gene in $\mathrm{C} 3 \mathrm{H} 10 \mathrm{~T} 1 / 2$ cells. The results obtained with the deletion mutants suggest that the $5^{\prime}$ upstream region may contain two separate elements, and both elements appear to be required for maximal activation of the S-phase-dependent CAT production. This is in contrast to the result obtained with the human $\mathrm{H} 2 \mathrm{~B}$ gene in HeLa cells, since the human $\mathrm{H} 2 \mathrm{~B}$ octamer element alone is sufficient for the S-phase-specific expression of the gene, although an upstream region containing the CCAAT element is also required for maximal transcriptional activity (24).

\section{DISCUSSION}

Testis-specific histones (TH1, TH2A, and TH2B) replace their somatic counterparts in pachytene spermatocytes of meiotic prophase I during spermatogenesis in various mammalian species $(4,27)$. The synthesis of testis-specific histone variants is independent of DNA replication $(6,27)$ and unaffected by inhibitors of DNA synthesis $(6,27)$. In situ cytohybridization with $\mathrm{H} 2 \mathrm{~B}-$ and TH2B-specific DNA probes also shows pachytene-specific transcription of the TH2B gene (21). On the other hand, expression of the H2B gene in spermatogenic cells occurs exclusively within the cell types undergoing DNA synthesis, such as spermatogonia (21). Therefore, the presence of S-phase-specific transcription regulatory elements in the upstream region of the TH2B gene is highly unusual. 

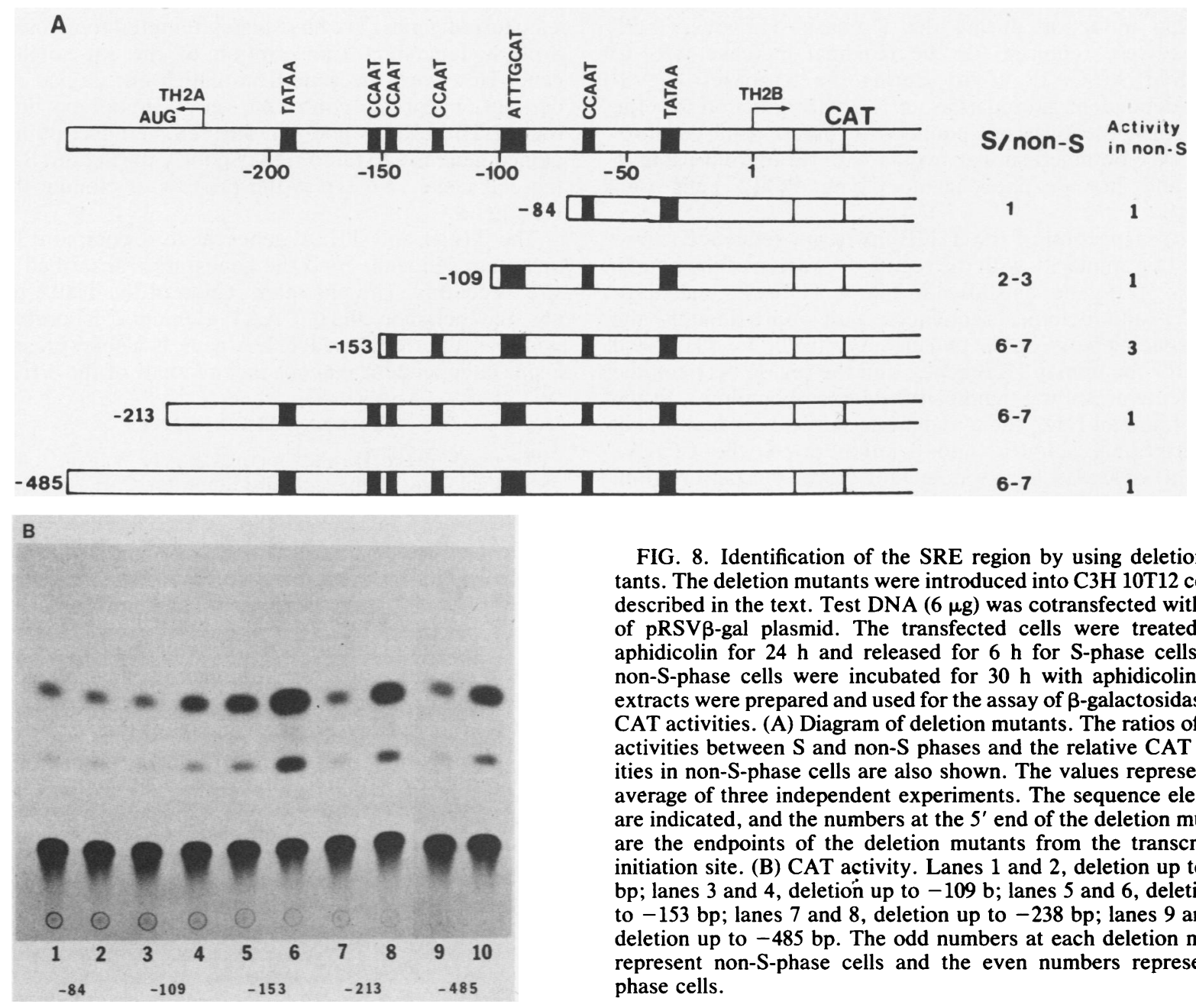

FIG. 8. Identification of the SRE region by using deletion mutants. The deletion mutants were introduced into $\mathrm{C} 3 \mathrm{H} 10 \mathrm{~T} 12$ cells as described in the text. Test DNA $(6 \mu \mathrm{g})$ was cotransfected with $5 \mu \mathrm{g}$ of pRSV $\beta$-gal plasmid. The transfected cells were treated with aphidicolin for $24 \mathrm{~h}$ and released for $6 \mathrm{~h}$ for S-phase cells. The non-S-phase cells were incubated for $30 \mathrm{~h}$ with aphidicolin. Cell extracts were prepared and used for the assay of $\beta$-galactosidase and CAT activities. (A) Diagram of deletion mutants. The ratios of CAT activities between $S$ and non-S phases and the relative CAT activities in non-S-phase cells are also shown. The values represent the average of three independent experiments. The sequence elements are indicated, and the numbers at the 5 ' end of the deletion mutants are the endpoints of the deletion mutants from the transcription initiation site. (B) CAT activity. Lanes 1 and 2, deletion up to -84 bp; lanes 3 and 4 , deletion up to -109 b; lanes 5 and 6 , deletion up to $-153 \mathrm{bp}$; lanes 7 and 8 , deletion up to $-238 \mathrm{bp}$; lanes 9 and 10 , deletion up to $-485 \mathrm{bp}$. The odd numbers at each deletion mutant represent non-S-phase cells and the even numbers represent $S$ phase cells.

The cloned rat TH2B gene was regulated in a cell cycledependent manner, like the somatic $\mathrm{H} 2 \mathrm{~B}$ gene, when the 1.4-kb DNA containing the intact TH2B gene was introduced into mouse embryo fibroblast $\mathrm{C} 3 \mathrm{H} 10 \mathrm{~T} 1 / 2$ cells. The level of TH2B mRNA, like that of endogenous mouse $\mathrm{H} 2 \mathrm{~B}$ mRNA, rose in parallel with the increase in DNA replication in $S$ phase and declined with the decrease in the rate of DNA synthesis. The result suggests not only that the cloned TH2B gene contains the regulatory elements for S-phase-specific transcription but also that the TH2B $3^{\prime}$-terminal hairpin loop sequence may be involved in the cell cycle-specific degradation of mRNA, as in somatic histone genes $(7,32,39,44)$. The replacement of the TH2B DNA downstream of the AUG codon with a reporter cat gene abolished the cell cycledependent decline of mRNA. Similar results were obtained with somatic histone genes $(32,39)$. The role of the TH2B
3 -terminal region in the cell cycle-dependent degradation of TH2B mRNA needs to be investigated in more detail. In this report, we have focused mainly on the characterization the S-phase-specific transcription element. We fused the 554-bp region upstream of the AUG codon of the TH2B gene with a reporter gene, cat. The cell cycle-dependent expression of the cat gene under the control of the TH2B gene upstream region was examined by transient expression of the gene in the protocol developed in this report. With this assay, we observed the S-phase-dependent increase of CAT activity, cellular cat mRNA, and transcription of the cat gene in the isolated $S$ phase nuclei. The $5^{\prime}$ deletion mutants showed that two regions located between -153 and -110 bp and between -109 and $-84 \mathrm{bp}$ from the transcription initiation site are important for the S-phase-dependent transcription. The region between -109 and -84 bp alone produced a two- to

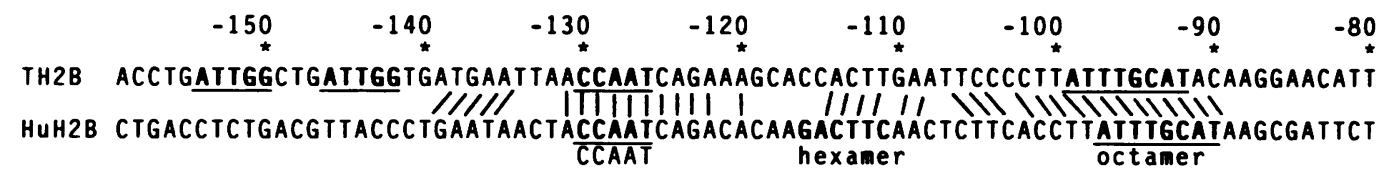

FIG. 9. Comparison of the TH2B and human somatic H2B gene upstream sequences. The CCAAT and octamer elements are indicated by bold letters. The hexamer sequence in the human H2B (HuH2B) gene is also indicated. Similar sequences between TH2B and human H2B genes are shown by connecting lines. The numbers indicate the positions of TH2B upstream sequences. 
threefold induction during the $\mathrm{S}$ phase. However, both regions were required for the maximal increase (six- to sevenfold) of CAT activity during the $S$ phase. The Sphase-dependent stimulation of CAT production by the TH2B promoter was not confined to mouse embryo fibroblasts. We obtained similar results with rat thyroid FRTL-5 cells and human pheochromocytoma PC-12 cells (not shown).

Close inspection of the TH2B upstream sequence shows interesting similarity with the regulatory region of the human somatic H2B gene, as shown in Fig. 9. The two genes have CCAAT and octamer sequences with approximately the same spacing between the two elements ( $26 \mathrm{bp}$ for TH2B and $28 \mathrm{bp}$ for the human H2B gene), and the region between the two elements shows significant sequence homology. In the case of human $\mathrm{H} 2 \mathrm{~B}$, the $5^{\prime}$ deletions showed gradual loss of transcriptional activity, and deletion up to the CCAAT element yielded a barely detectable level of transcription. However, the S-phase-dependent stimulatory activity was not affected by the deletions, and only the octamer element appeared to be responsible for the S-phase-dependent stimulation of transcription $(11,24)$. In contrast, the TH2B gene has two regions which show S-phase-dependent stimulation of gene transcription. One region, between -109 and -153 $\mathrm{bp}$, contains three CCAAT elements, and the region between -84 and -109 bp contains an octamer element. The region between -109 and -153 bp has two activities: stimulation of gene transcription (about threefold) and stimulation of transcription in S phase. Recent experiments in our laboratory show that there is a protein which binds to the CCAAT element proximal to the octamer, and mutations of the element diminish the S-phase-dependent stimulation. Also, the spacing between the CCAAT and octamer element appears to be important for the maximal stimulation of transcription in $\mathrm{S}$ phase (manuscript in preparation). The CCAAT element is also important for the S-phase-dependent transcription of thymidine kinase gene (22). The octamer element may mediate the action of the CCAAT element in the TH2B gene. In the herpesvirus thymidine kinase gene, the activity of upstream enhancers is mediated by the octamer element (33).

In summary, there are similarities (S-phase-dependent stimulation by octamer) as well as differences in the regulation of S-phase-dependent stimulation of transcription between the TH2B and human H2B genes. Since TH2B gene expression is independent of the $S$ phase of the cell cycle in vivo and specific for the pachytene spermatocytes, it is surprising that the $\mathrm{S}$-phase-specific transcription elements are retained in the TH2B gene. The conservation of these elements suggests that the DNA elements may be used for the pachytene-specific transcription of the TH2B gene in vivo but repressed in somatic cells as well as in other spermatogenic cells. Recent experiments in our laboratory show that the TH2B gene in a much larger DNA fragment $(6.5 \mathrm{~kb})$ is inactive when introduced into somatic cells such as $\mathrm{C} 3 \mathrm{H} 10 \mathrm{~T} 1 / 2$, rat thyroid, and placental cells (unpublished results). Therefore, it is possible that there is an inhibitory cis-acting DNA sequence element near the TH2B gene. Alternatively, the S-phase-specific regulatory elements may be repressed even in pachytene spermatocytes, and pachytene-specific regulatory elements may be required for transcription of the TH2B gene in pachytene spermatocytes. Presently, there is no long-term culture system for pachytene spermatocytes, and we are in the process of developing optimum conditions for gene transfer into primary culture of spermatocytes and identification of the cells expressing transferred genes. We have also attempted to investigate the $\mathrm{S}$-phase-dependent transcription of the rat somatic H2B gene. However, the gene from which our cloned gene was derived appears to contribute only a minor portion of the total H2B mRNA pool in the cell. Transcription of the cloned gene is activated rather poorly during the $S$ phase of the cell cycle. We are in the process of cloning the major $\mathrm{H} 2 \mathrm{~B}$ gene.

The TH2B and TH2A genes have a common 200-bp 5' upstream sequence, and the genes are transcribed in opposite directions. The upstream region of the TH2A gene also has the octamer and CCAAT elements. Therefore, it is possible that the cloned $\mathrm{TH} 2 \mathrm{~A}$ gene is also expressed in an $\mathrm{S}$-phase-dependent manner independent of the $\mathrm{TH} 2 \mathrm{~B}$ gene.

\section{ACKNOWLEDGMENTS}

We thank Bruce Howard for pSV2CAT, William J. Rutter for pRSV $\beta$-gal, and Marila Cordeiro-Stone for C3H 10T1/2 cells and advice on cell synchrony. Aphidicolin was provided by the Natural Products Branch, National Cancer Institute.

This work was supported by Public Health Service grant HD20136 from the National Institute of Child Health and Human Development.

\section{LITERATURE CITED}

1. Alterman, R.-B. M., C. Sprecher, R. Graves, W. F. Marzluff, and A. I. Skoultchi. 1985. Regulated expression of a chimeric histone gene introduced into mouse fibroblasts. Mol. Cell. Biol. 5:2316-2324.

2. An, G., K. Hidaka, and L. Siminovitch. 1982. Expression of bacterial $\beta$-galactosidase in animal cells. Mol. Cell. Biol. 2: 1628-1632.

3. Artishevsky, A., S. Wooden, A. Sharma, E. Resendez, Jr., and A. S. Lee. 1987. Cell-cycle regulatory sequences in a hamster histone promoter and their interactions with cellular factors. Nature (London) 328:823-827.

4. Branson, R. E., S. R. Grimes, G. Yonuschot, and J. L. Irvin. 1975. The histones of rat testis. Arch. Biochem. Biophys. 168:403-412.

5. Chirgwin, J. M., A. E. Przybyla, R. J. MacDonald, and W. J. Rutter. 1979. Isolation of biologically active ribonucleic acid from sources enriched in ribonuclease. Biochemistry 18:5294 5299.

6. Chiu, M., and J. L. Irvin. 1985. Effect of inhibition of DNA synthesis on histone synthesis, turnover, and deposition in the rat testis. Arch. Biochem. Biophys. 236:260-265.

7. Chodchoy, N., B. J. Levine, C. Sprecher, A. I. Skoultchi, and W. F. Marzluff. 1987. Expression of mouse histone gene: transcription into $3^{\prime}$ intergenic DNA and cryptic processing sites downstream from the $3^{\prime}$ end of the $\mathrm{H} 3$ gene. Mol. Cell. Biol. 7:1039-1047.

8. Cole, K. D., J. C. Kandala, and S. Kistler. 1986. Isolation of the gene for the testis-specific $\mathrm{H} 1$ histone variant H1t. J. Biol. Chem. 261:7178-7183.

9. Cordeiro-Stone, M., and D. G. Kaufman. 1984. Kinetics of DNA replication in $\mathrm{C} 3 \mathrm{H} 10 \mathrm{~T} 1 / 2$ cells synchronized by aphidicolin. Biochemistry 24:4815-4822.

10. Dale, R. M. K., B. A. McClure, and J. P. Houchins. 1985. A rapid single-stranded cloning strategy for producing a sequential series of overlapping clones for use in DNA sequencing: application to sequencing the corn mitochondrial $18 \mathrm{~S}$ rDNA. Plasmid 13:31-40.

11. Dalton, S., J. R. Coleman, and J. R. E. Wells. 1986. Transcription of the histone $\mathrm{H} 5$ gene is not S-phase regulated. Mol. Cell. Biol. 6:601-606.

12. Edlund, T., M. D. Walker, P. J. Barr, and W. J. Rutter. 1985. Cell-specific expression of the rat insulin gene: evidence for role of two distinct $5^{\prime}$-flanking elements. Science 230:912-916.

13. Feinberg, A. P., and B. Vogelstein. 1983. A technique for radiolabeling DNA restriction endonuclease fragments to high specific activity. Anal. Biochem. 132:6-13. 
14. Fletcher, C., N. Heintz, and R. G. Roeder. 1987. Purification and characterization of OTF-1, a transcription factor regulating cell cycle expression of a human histone $\mathrm{H} 2 \mathrm{~b}$ gene. Cell 51:773-781.

15. Gorman, C. 1985. High-efficiency gene transfer into mammalian cells, p. 143-190. In D. M. Glover (ed.), DNA cloning: a practical approach, vol. 2. IRL Press, Washington, D.C.

16. Gorman, C. M., L. F. Moffat, and B. H. Howard. 1982. Recombinant genomes which express chloramphenicol acetyltransferase in mammalian cells. Mol. Cell. Biol. 2:1044-1051.

17. Gorman, C. M., R. Padmanabhan, and B. H. Howard. 1983. High-efficiency DNA-mediated transformation of primate cells. Science 221:551-553.

18. Groudine, M., M. Peretz, and H. Weintraub. 1981. Transcriptional regulation of hemoglobin switching in chicken embryos. Mol. Cell. Biol. 1:281-288.

19. Heintz, N., H. L. Sive, and R. Roeder. 1983. Regulation of human histone gene expression: kinetics of accumulation and changes in the rate of synthesis and in half-lives of individual histone mRNAs during HeLa cell cycle. Mol. Cell. Biol. 3: 539-550.

20. Hereford, L. M., M. A. Osley, J. R. Ludwig, and C. S. McLaughlin. 1981. Cell cycle regulation of yeast histone mRNA. Cell 24:367-375

21. Kim, Y.-J., I. Hwang, L. L. Tres, A. L. Kierzenbaum, and C.-B. Chae. 1987. Molecular cloning and differential expression of somatic and testis-specific $\mathrm{H} 2 \mathrm{~B}$ histone genes during rat spermatogenesis. Dev. Biol. 124:23-34.

22. Knight, G. B., J. M. Gudas, and A. B. Pardee. 1987. Cellcycle-specific interaction of nuclear DNA-binding proteins with a CAAT sequence from the human thymidine kinase gene. Proc. Natl. Acad. Sci. USA 84:8350-8354.

23. Kroeger, P., C. Stewart, T. Schaap, A. van Wijnen, J. Hirshman, S. Helms, G. Stein, and J. Stein. 1987. Proximal and distal regulatory elements that influence in vivo expression of a cell cycle-dependent human $\mathrm{H} 4$ histone gene. Proc. Natl. Acad. Sci. USA 84:3982-3986.

24. LaBella, F., H. L. Sive, R. G. Roeder, and N. Heintz. 1988. Cell-cycle regulation of a human histone $\mathrm{H} 2 \mathrm{~b}$ gene is mediated by the $\mathrm{H} 2 \mathrm{~b}$ subtype-specific consensus element. Genes Dev. 2:32-39.

25. Lassar, A. B., B. M. Paterson, and H. Weintraub. 1986. Transfection of a DNA locus that mediates the conversion of $10 \mathrm{~T} 1 / 2$ fibroblasts to myoblasts. Cell 47:649-656.

26. Maniatis, T., E. F. Fritsch, and J. Sambrook. 1982. Molecular cloning: a laboratory manual. Cold Spring Harbor Laboratory, Cold Spring Harbor, N.Y.

27. Meistrich, M. L. 1987. Proteins of the meiotic cell nucleus, p. 333-353. In P. B. Moens (ed.), Meiosis. Academic Press, New York.

28. Melton, D. A., P. A. Krieg, M. R. Rebagliati, T. Maniatis, K. Zinn, and M. R. Green. 1984. Efficient in vitro synthesis of biologically active RNA and RNA hybridization probes from plasmids containing a bacteriophage SP6 promoter. Nucleic Acids Res. 12:7035-7056.

29. Morris, T., F. Marashi, L. Weber, E. Hickey, D. Greenspan, J. Bonner, J. Stein, and G. Stein. 1986. Involvement of the 5 -leader sequence in coupling the stability of a human $\mathrm{H} 3$ histone mRNA with DNA replication. Proc. Natl. Acad. Sci.
USA 83:981-985.

30. Old, R. W., and H. R. Woodland. 1984. Histone genes: not so simple after all. Cell 38:624-626.

31. Osley, M. A., J. Gould, S. Kim, M. Kane, and L. Hereford. 1986. Identification of sequences in a yeast histone promoter involved in periodic transcription. Cell 45:537-544.

32. Pandey, N. B., and W. Marzluff. 1987. The stem-loop structure at the $3^{\prime}$ end of histone mRNA is necessary and sufficient for regulation of histone mRNA stability. Mol. Cell. Biol. 7:45574559.

33. Panslow, T. J., S. D. Jones, B. Bond, and K. R. Yamamoto. 1987. The immunoglobulin octanucleotide: independent activity and selective interaction with enhancers. Science 235:1498-1987.

34. Prywes, R., and R. G. Roeder. 1986. Inducible binding of a factor to the c-fos enhancer. Cell 47:777-784.

35. Rickles, R., F. Marash, F. Sierra, J. Clark, J. Wells, J. Stein, and G. Stein. 1982. Analysis of histone gene expression during the cell cycle in HeLa cells by using cloned human histone genes. Proc. Natl. Acad. Sci. USA 79:749-753.

36. Robbin, S. E., and T. W. Borun. 1967. The cytoplasmic synthesis of histones in HeLa cells and its temporal relationship to DNA replication. Proc. Natl. Acad. Sci. USA 57:409-418.

37. Sanger, F., S. Nicklen, and A. R. Coulson. 1977. DNA sequencing with chain-terminating inhibitors. Proc. Natl. Acad. Sci. USA 74:5463-5468.

38. Sargent, T. D., J.-R. Wu, J. M. Sala-Trepat, R. B. Wallace, A. T. Reyes, and J. Bonner. 1979. The rat serum albumin gene: analysis of cloned sequences. Proc. Natl. Acad. Sci. USA 76:3256-3260.

39. Seiler-Tuyns, A., and B. M. Paterson. 1986. A chimeric mouse histone $\mathrm{H} 4$ gene containing either an intron or poly(A) addition signal behaves like a basal histone. Nucleic Acids Res. 14: 8845-8862.

40. Seiler-Tuyns, A., and B. M. Paterson. 1987. Cell cycle regulation of a mouse histone $\mathrm{H} 4$ gene requires the $\mathrm{H} 4$ promoter. Mol. Cell. Biol. 7:1048-1054.

41. Sittman, D. B., R. A. Graves, and W. F. Marzluff. 1983. Histone mRNA concentrations are regulated at the level of transcription and mRNA degradation. Proc. Natl. Acad. Sci. USA 80: 1849-1853.

42. Sive, H. L., N. Heintz, and R. G. Roeder. 1986. Multiple sequence elements are required for maximal in vitro transcription of a human histone H2B gene. Mol. Cell. Biol. 6:3329-3340.

43. Sive, H. L., and R. Roeder. 1986. Interaction of a common factor with conserved promoter and enhancer sequences in histone H2B, immunoglobulin, and U2 small nuclear RNA (snRNA) genes. Proc. Natl. Acad. Sci. USA 83:6382-6386.

44. Stauber, C., B. Luscher, R. Eckner, E. Lotscher, and D. Schumperli. 1986. A signal regulating mouse histone H4 mRNA levels in a mammalian cell cycle mutant and sequences controlling RNA $3^{\prime}$ processing are both contained within the same 80-bp fragment. EMBO J. 5:3297-3303.

45. Tsai, Y. H., and L. S. Hnilica. 1975. Tissue specific histones in the erythrocytes of chicken and turtle. Exp. Cell Res. 91: 107-112.

46. Wells, D., and L. Kedes. 1985. Structure of a human histone cDNA: evidence that basically expressed histone genes have intervening sequences and encode polyadenylated mRNAs. Proc. Natl. Acad. Sci. USA 82:2834-2838. 